\title{
Calibration and validation of a MCC/IMS prototype for exhaled propofol online measurement
}

\author{
Felix Maurer ${ }^{\mathrm{a}, *}$, Larissa Walter ${ }^{\mathrm{a}, \mathrm{b}}$, Martin Geiger ${ }^{\mathrm{a}}$, Jörg Ingo Baumbach ${ }^{\mathrm{b}}$, \\ Daniel I. Sessler ${ }^{c}$, Thomas Volk ${ }^{a}$, Sascha Kreuer ${ }^{a}$ \\ a CBR-Centre of Breach Research, Department of Anaesthesiology, Intensive Care and Pain Therapy, Saarland University Medical Centre and Saarland \\ University Faculty of Medicine, 66424 Homburg, Saar, Germany \\ ${ }^{\mathrm{b}}$ Faculty Applied Chemistry, Reutlingen University, Alteburgstrasse 150, 72762 Reutlingen, Germany \\ ' Michael Cudahy Professor E' Chair, Department of OUTCOMES RESEARCH, Anesthesiology Institute, Cleveland Clinic, Cleveland, Ohio, USA The Centre of \\ Breath Research is part of the OUTCOMES RESEARCH Consortium, Cleveland, OH, USA
}

\section{A R T I C L E I N F O}

\section{Article history:}

Received 1 June 2017

Received in revised form 19 June 2017

Accepted 22 June 2017

Available online 1 July 2017

\section{Keywords:}

Propofol

Drug monitoring

Multi-capillary column coupled

ion-mobility spectrometer

Calibration

Anesthesia

Breath analysis

\begin{abstract}
A B S T R A C T
Propofol is a commonly used intravenous general anesthetic. Multi-capillary column (MCC) coupled Ionmobility spectrometry (IMS) can be used to quantify exhaled propofol, and thus estimate plasma drug concentration. Here, we present results of the calibration and analytical validation of a MCC/IMS premarket prototype for propofol quantification in exhaled air. Calibration with a reference gas generator yielded an $\mathrm{R}^{2} \geq 0.99$ with a linear array for the calibration curve from 0 to $20 \mathrm{ppb}_{\mathrm{v}}$. The limit of quantification was $0.3 \mathrm{ppb}_{\mathrm{v}}$ and the limit of detection was $0.1 \mathrm{ppb}_{\mathrm{v}}$. The device is able to distinguish concentration differences $>0.5 \mathrm{ppb}_{\mathrm{v}}$ for the concentration range between 2 and $4 \mathrm{ppb}_{\mathrm{v}}$ and $>0.9 \mathrm{ppb}_{\mathrm{v}}$ for the range between 28 and $30 \mathrm{ppb}_{\mathrm{v}}$. The imprecision at $20 \mathrm{ppb}_{\mathrm{v}}$ is $11.3 \%$ whereas it is $3.5 \%$ at a concentration of 40 $\mathrm{ppb}_{\mathrm{v}}$. The carry-over duration is $3 \mathrm{~min}$. The MCC/IMS we tested provided online quantification of gaseous propofol over the clinically relevant range at measurement frequencies of one measurement each minute.

(C) 2017 Elsevier B.V. All rights reserved.
\end{abstract}

\section{Introduction}

The dosing of propofol during anesthesia is usually based on morphometric characteristics and clinical needs. However, the relationship between administered dose and blood concentrations varies considerably from person-to-person as a function of drug distribution and metabolism. Concentrations estimated from pharmacokinetic equations can thus differ substantially from measured values. Excessive propofol concentrations may provoke haemodynamic instability and delayed recovery, whereas inadequate concentrations increase the risk for awareness and recall [1]. Real-time monitoring of propofol blood concentration thus seems preferable to pharmacokinetic estimates.

A series of studies using various devices have shown that propofol is detectable in patients' breath [2-6] over the clinically relevant range of $0-39 \mathrm{ppb}_{\mathrm{v}}$ [7], and that exhaled concentrations correlate with plasma concentrations [3]. Propofol can be quantified in

\footnotetext{
* Corresponding author at: Kirrbergerstrasse 100, building 56, 66424 Homburg, Saar, Germany.

E-mail address: Felix.Maurer@uks.eu (F. Maurer).
}

exhaled air with multi-capillary column ion mobility spectrometry (MCC/IMS) $[5,8,9]$ during anesthesia at a rate of once per minute. However, signals from MCC/IMS systems are in volts so calibration is necessary for comparison with other devices or to estimate plasma concentration. Our goal was thus to calibrate a pre-market prototype MCC/IMS system designed for online measurement of exhaled propofol.

We established a propofol calibration method for MCC/IMS devices using a commercial reference gas generator. Recently, we cross-validated the reference gas generator calibration by gas-chromatography coupled mass spectrometry (GC-MS) measurements of liquid injected sorbent tubes [10]. With the reference gas generator we tend now to calibrate and analytically validate a pre-market prototype for online measurement of exhaled propofol.

\section{Materials and methods}

\subsection{MCC/IMS parameters}

The pre-market prototype MCC/IMS system (B\&S Analytik, Dortmund, Germany) has an OV5 MCC (Multichrom Ltd, Novosibirsk, Russia) of $12 \mathrm{~cm}$ length and with a temperature of $90^{\circ} \mathrm{C}$, providing 
a retention time of $23 \mathrm{~s}$ for propofol. After pre-separation, ionization is performed by a $\mathrm{Ni}^{63} \beta$-radiation source. Ions enter the $20 \mathrm{~cm}$ long drift region through a Bradbury-Nielsen grid which is opened every $50 \mathrm{~ms}$ for $300 \mu \mathrm{s}$.

As drift and carrier gas synthetic air (Air Liquide, Düsseldorf, Germany) (20.5\% $\pm 0.5 \mathrm{O}_{2}$ in $\mathrm{N}_{2}$, purity $\left.\geq 99.999 \%\right)$ was used. The gas flows were $100 \mathrm{~mL} \mathrm{~min}^{-1}$ for sample loop flushing, $150 \mathrm{~mL} \mathrm{~min}^{-1}$ in the MCC and $100 \mathrm{~mL} \mathrm{~min}^{-1}$ in the drift tube. Samples were collected for $20 \mathrm{~s}$ at $1-\mathrm{min}$ intervals with a gas flow of $350 \mathrm{~mL} \mathrm{~min}^{-1}$.

\subsection{Calibration gas generator parameters}

A calibration gas generator model HovaCAL 4836-VOC (IAS, Oberursel, Germany) [11] was used with a calibration gas flow of $850 \mathrm{~mL} \mathrm{~min}^{-1}$. Dosing syringes with a volume of $12.5,50,125$ and $250 \mu \mathrm{L}$ were purchased (Hamilton, Planegg, Germany). The propofol solution was vaporized at a temperature of $100^{\circ} \mathrm{C}$. Pure water (B. Braun Melsungen, Melsungen, Germany) was simultaneously evaporated to provide a relative humidity of $100 \%$ at the selected reference temperature of $37^{\circ} \mathrm{C}$, representing physiologic conditions. The carrier gas was $\mathrm{N}_{2}$ (purity 3.5). ViewCAL 1.2.1 (IAS, Oberursel, Germany) software was used for HovaCAL control.

\subsubsection{Stock solution}

A $90 \mu \mathrm{g} \mathrm{mL}^{-1}$ propofol solution was used for all measurements. It was prepared by dissolving propofol $\geq 97 \%$ (Sigma Aldrich, Steinheim, Germany) in $1 \%$ v/v absolute ethanol (Sigma-Aldrich, Steinheim, Germany) in HPLC-grade water (VWR, Darmstadt, Germany). Propofol was gravimetrical dosed with an analytical balance model MSA225P-1CE-DU (Sartorius, Goettingen, Germany) to calculate the exact mass of the propofol concentration in solvent. The stock solution was kept in a $250 \mathrm{~mL}$ glass bottle and freshly prepared once per week.

\subsection{Experimental setup}

The propofol gas was piped through a $2 \mathrm{~m}$ long $50^{\circ} \mathrm{C}$ heated PFA transfer tubing (IAS, Oberursel, Germany) to the sample-in of the MCC/IMS. The tubing contains a stainless steel $1 / 8$ " t-piece (Swagelok, Frankfurt, Germany) in the middle to avoid build-up of internal pressure. The experimental setup is illustrated in Fig. 1.

\subsection{Calibration}

The following propofol concentrations were produced by the reference gas generator and measured with the MCC/IMS: 60,50 , $40,30,20,10$, and $5 \mathrm{ppb}_{\mathrm{v}}$. Each concentration was held for $30 \mathrm{~min}$, corresponding to 30 measurements. Before and after each concentration, 15 blank measurements were obtained. For dosing into the HovaCAL, a syringe volume of $50 \mu \mathrm{L}$ was used from 5 to $30 \mathrm{ppb}_{\mathrm{v}}$ and a $125 \mu \mathrm{L}$ syringe was used for the higher concentrations.

\subsection{Validation}

\subsubsection{Linearity}

The measured MCC/IMS signal intensity of propofol was plotted vs. the gas concentration of propofol from HovaCAL, excepting the five initial and final measurements at each concentration. Linear regression was used to determine the slope, intercept, and linear range.

\subsubsection{Limit of detection/limit of quantification}

The limit of quantification (LOQ) as well as the limit of detection (LOD) were determined according to the International Conference on Harmonisation of "Technical Requirements for Registration of
Pharmaceuticals for Human Use," [12] and based on the signal-tonoise ratio of 3:1 for LOD and 10:1 for LOQ. Specifically, the test concentration was decreased in $0.1 \mathrm{ppb}_{\mathrm{v}}$ decrements from an initial concentration of $1 \mathrm{ppb}_{\mathrm{v}}$. Each concentration was maintained for $20 \mathrm{~min}$. The noise was calculated as the mean intensity of 10 initial blank measurements.

\subsubsection{Precision}

Precision of the method was analyzed by holding a concentration of $20 \mathrm{ppb}_{\mathrm{v}}$ respectively $40 \mathrm{ppb}_{\mathrm{v}}$ for two hours with the reference generator while continuously measuring with MCC/IMS. The standard deviation was determined and imprecision was additionally estimated as difference between the largest and smallest measured value as a percentage of the mean.

\subsubsection{Carry over}

Concentrations of $20 \mathrm{ppb}_{\mathrm{v}}$ and $40 \mathrm{ppb}_{\mathrm{v}}$ were maintained for $1 \mathrm{~h}$ before changing the concentration to $0 \mathrm{ppb}_{\mathrm{v}}$. Concentrations were assayed over the subsequent $15 \mathrm{~min}$ to determine the time required for the propofol signal to disappear.

\subsubsection{Resolution}

The resolution was tested in the concentration ranges from 2 to $4 \mathrm{ppb}_{\mathrm{v}}$ and 28 to $30 \mathrm{ppb}_{\mathrm{v}}$ in $0.2 \mathrm{ppb}_{\mathrm{v}}$ steps. One concentration was held for 20 min with 5 blank measurements before and after each concentration. For dosing into the HovaCAL $50 \mu \mathrm{L}$ syringes were utilized.

\subsection{Data analysis}

Data analysis for IMS spectra and peak intensities was performed by VisualNow 3.7 (B\&S Analytik, Dortmund, Germany).

\subsection{Statistical analysis}

Statistical analyses were conducted with SigmaPlot (version 12.5, Systat Software, Erkrath, Germany) using repeated-measures one-way ANOVA for normally distributed data. Alternatively, a repeated-measures one-way ANOVA on ranks was performed. Normality was determined by Shapiro-Wilk test. $P<0.05$ was considered significant.

\section{Results}

Fig. 2 shows the MCC/IMS signal intensity in volts vs. the propofol gas concentration in $\mathrm{ppb}_{\mathrm{v}}$ of the reference gas generator. The middle 20 (of 30) values of each concentration were evaluated (blue dots). The exponential calibration curve (red line) shows a coefficient of determination $\geq 0.99$. The linear range is short. A linear fitting with a coefficient of determination of 0.92 is just available between 0 and $20 \mathrm{ppb}_{\mathrm{v}}$.

The calculations based on the signal-to-noise ratio, provided a LOD of $85 \mathrm{ppt}_{\mathrm{v}}(0.004 \mathrm{~V})$ and a LOQ of $258 \mathrm{ppt}_{\mathrm{v}}(0.012 \mathrm{~V})$. The corresponding peaks are shown in Fig. 3.

The precision measurements at $20 \mathrm{ppb}_{\mathrm{v}}$ and $40 \mathrm{ppb}_{\mathrm{v}}$ had a relative standard deviation of $1.8 \%$ and $0.8 \%$ and a statistical range of $11.3 \%$ and $3.5 \%$ of the mean. The statistical range at $40 \mathrm{ppb}_{\mathrm{v}}$ is small because of the non-linear measurement range of the device at 40 $\mathrm{ppb}_{\mathrm{v}}$.

The carry-over was measured after changing a concentration of $20 \mathrm{ppb}_{\mathrm{v}}$ and $40 \mathrm{ppb}_{\mathrm{v}}$ to $0 \mathrm{ppb}_{\mathrm{v}}$. The first value after the propofol evaporation stopped shows a carry-over of 3.5\% respectively $6.1 \%$ of the average signal intensity at $20 \mathrm{ppb}_{\mathrm{v}}$ and $40 \mathrm{ppb}_{\mathrm{v}}$.

The resolution was evaluated between 2 and $4 \mathrm{ppb}_{\mathrm{v}}$ and $28-30$ $\mathrm{ppb}_{\mathrm{v}}$. The measurements between 2 and $4 \mathrm{ppb}_{\mathrm{v}}$ (Fig. 4 upper left) can be described with a linear fit yielding an $R^{2}=0.96$. Using the $95 \%$ 


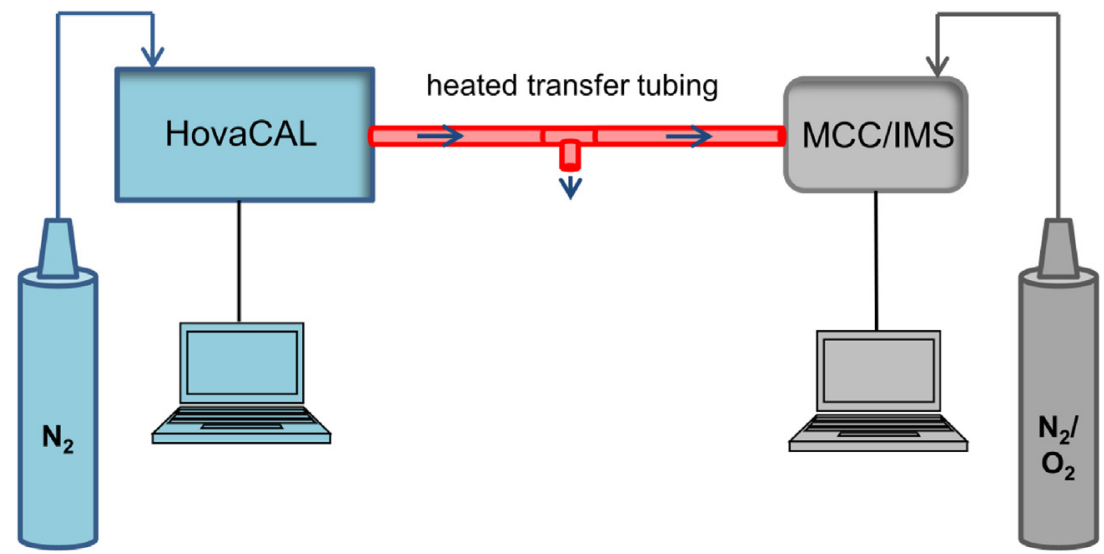

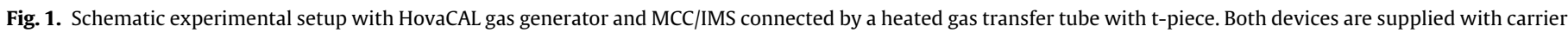
gas and are controlled by an external software.

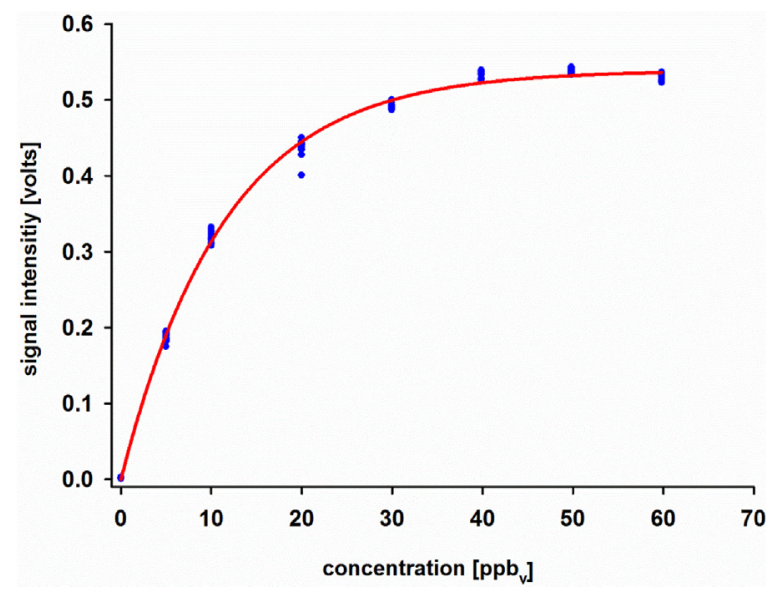

Fig. 2. MCC-IMS calibration with 20 values (blue dots) at each concentration over the range from 0 to $60 \mathrm{ppb}_{\mathrm{v}}$. The calibration curve in red increases exponentially: $f(x)=0.5392$ (1-exp-0.0873) with $R^{2} \geq 0.99$. (For interpretation of the references to colour in this figure legend, the reader is referred to the web version of this article.)

prediction interval (red lines), upper and lower prediction boarders for $0.1 \mathrm{~V}$ can be calculated in $\mathrm{ppb}_{\mathrm{v}}$. The predicted $\mathrm{ppb}_{\mathrm{v}}$ range for $0.1 \mathrm{~V}$ has a width of $0.5 \mathrm{ppb}_{\mathrm{v}}\left(2.6-3.1 \mathrm{ppb}_{\mathrm{v}}\right)$. Hence, the minimal distinguishable concentration difference in this measurement range is $>0.5 \mathrm{ppb}_{\mathrm{v}}$.

The measuring range between 28 and $30 \mathrm{ppb}_{\mathrm{v}}$ shows a correlation coefficient of 0.81 for a linear fit and 0.87 for a polynomial fit. The predicted $\mathrm{ppb}_{\mathrm{v}}$ range for $0.5 \mathrm{~V}$ has a width of $1.2 \mathrm{ppb}_{\mathrm{V}}$ (28.1-29.3 $\mathrm{ppb}_{\mathrm{v}}$ ) for the linear fit and narrows down to $0.9 \mathrm{ppb}_{\mathrm{v}}$
(28.1-29.0 $\mathrm{ppb}_{\mathrm{v}}$ ) when the polynomial fit is used. In this measurement range the differentiation between individual concentrations is possible for differences $>0.9 \mathrm{ppb}_{\mathrm{v}}$.

\section{Discussion}

The propofol calibration curve shows a short linear range and therefore the device is hardly able to differentiate signals above $0.5 \mathrm{~V}$. Several publications reported an expected clinical relevant concentration range between 0 and $39 \mathrm{ppb}_{\mathrm{v}}[2,3,6,9,13-15]$. Based on these publications, the linear range of the device is too short for the clinical quantification of propofol in breath. However, one other study based on three patients reported a propofol breath concentration of $0.0043 \mathrm{ppb}_{\mathrm{v}}-0.0335 \mathrm{ppb}_{\mathrm{v}}$ during anesthesia [16]. How this much lower range can be explained remains unclear, but the detected concentration can be influenced by diverse factors as sampling duration and volume, measurement method and many more. As the study of Gong and co-authors is based only on 9 data points, the power is limited. It is probable that the average propofol concentration during anesthesia is higher than reported in that study.

Since the linear range is optimal for quantification measurements the precision at $20 \mathrm{ppb}_{\mathrm{v}}$ is of particular interest. The statistical range of the precision was evaluated $11.3 \%$ for $20 \mathrm{ppb}_{\mathrm{v}}$. It is difficult to determine if this statistical range is tolerable for clinical measurements. Although the correlation between propofol blood and breath concentration has been described by several pharmacokinetic modeling approaches in humans [17,18], further studies are needed to design models suitable for clinical practice. The impact of an $11.3 \%$ imprecision in breath on the estimation

\section{Noise}

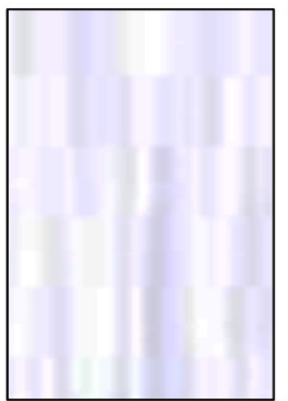

LOD

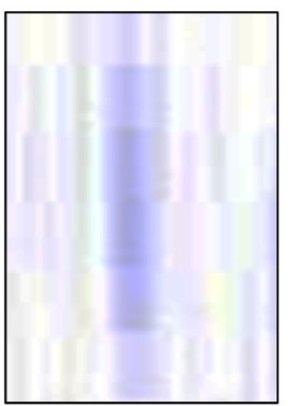

LOQ

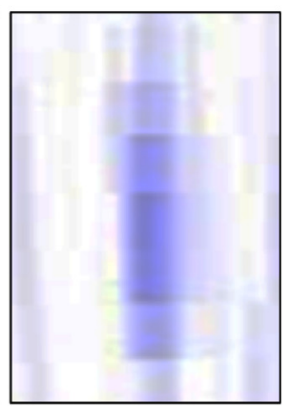

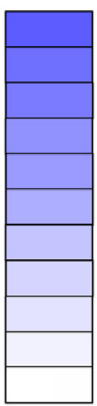

$260 \mathrm{ppt}_{\mathrm{v}}$

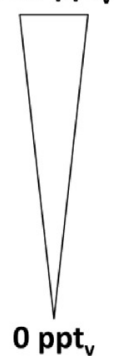

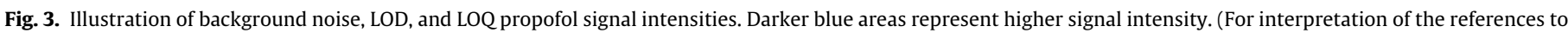
colour in this figure legend, the reader is referred to the web version of this article.) 

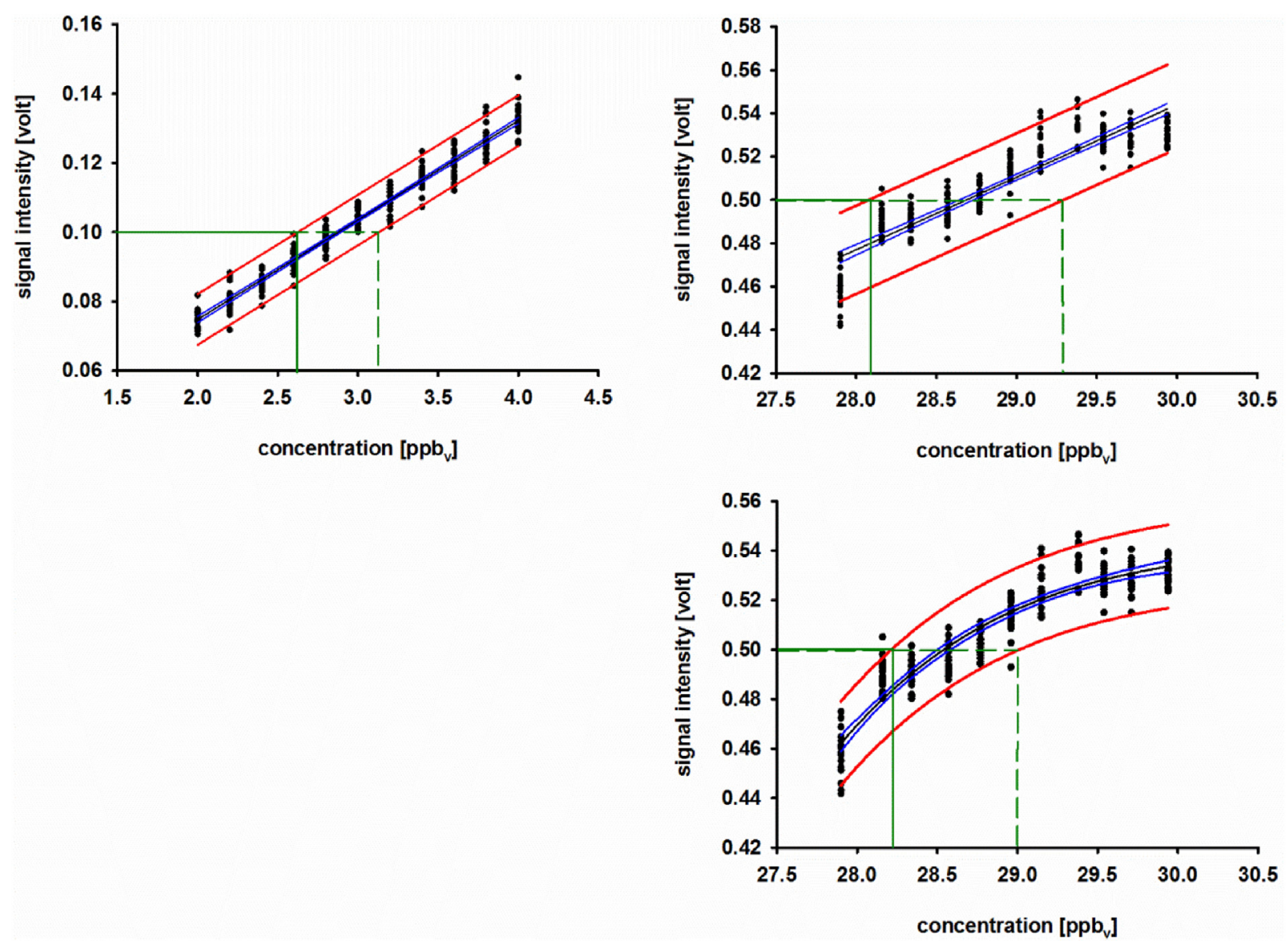

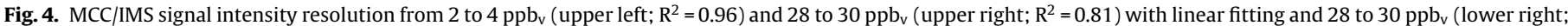

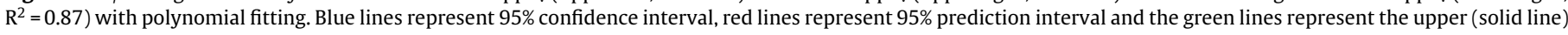

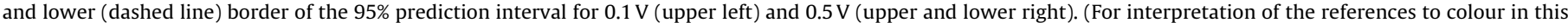
figure legend, the reader is referred to the web version of this article.)

of blood concentration is thus unclear. From an analytical point of view a deviation up to $15 \%$ is commonly considered satisfactory.

A carry over effect could be observed in the first minute after a concentration change with a value below $7 \%$ of the average signal intensity for $40 \mathrm{ppb}_{\mathrm{v}}$. A reason for the effect could be the adhesion of propofol to the inner surfaces of the HovaCAL and the MCC/IMS. Interactions of gaseous propofol with plastic surfaces have been investigated [19]. Plastic in form of polytetrafluorethylene (PTFE) tubing is installed in the MCC/IMS as gas-conveying line. Further sorption sites in the reference gas generator are stainless steel elements, syringes consisting of glass, or glass bottles with plastic lock. Potentially all of these surfaces can contribute to the carry over. However, after three measurements at one-minute intervals, the carry-over was only $2.4 \%$ at $0 \mathrm{ppb}_{\mathrm{v}}$, and thereby lower than the imprecision of our method. Furthermore, the low carry over after just one minute of washout is suitable for clinical use.

Also the limits of detection and quantification with values of 85 $\mathrm{ppt}_{\mathrm{v}}$ and $258 \mathrm{ppt}_{\mathrm{v}}$ are lower than required for quantitative breath measurements during anesthesia as breath concentrations are in the ppb range. Furthermore the limits are considerably lower than those reported by Perl and colleagues in a similar setup with MCCIMS [9]. The technical parts of the used prototype were redesigned and optimized for propfol measurement. This included changing the material of all used tubes and a $2 \mathrm{~mL}$ higher volume of the sample loop. An increased loop volume leads to a higher sample volume. Therefore, the detection and quantification limits are lower in our MCC/IMS.
The validation of the resolution obtained minimal distinguishable concentration differences of $>0.5 \mathrm{ppb}_{\mathrm{v}}$ for the lower concentration range and $>0.9 \mathrm{ppb}_{\mathrm{v}}$ for the upper concentration range. Therefore, the resolution over the tested concentration ranges is sufficient for clinical needs.

Our calibration and validation of MCC/IMS is based on measurements of defined propofol gas concentrations. The gas was produced with a reference gas generator, which is more elegant than headspace measurements [20] or gas dilution in Tedlar bags [16]. Nevertheless, the gas concentrations can be inaccurate for two reasons: First, the generator estimates concentrations using ideal gases laws, which is the same for all common methods, but is not exactly correct. However, it can be assumed that the related deviation is negligibly small. Second, inner surfaces can lead to carry over and falsify the concentration of the output gas at least as long as sorption and desorption are not in equilibrium. However, the calibration with the reference gas generator was cross-validated with a liquid injection to sorbent tubes for thermal desorption GC-MS [10]. When we compared the method to the liquid injection technique, the reference gas generator method showed satisfactory limits of agreement and a good accordance.

We aimed to calibrate and analytically validate a pre-market prototype for online measurement of exhaled propofol. The calibration technique proved to be uncomplicated and fast. The limit of detection and quantification were sufficiently to permit propofol quantification over the full clinical range. 


\section{Conclusions}

The calibration and validation procedure of a pre-market prototype MCC/IMS with a reference gas generator was successfully established. The validation demonstrated that the analytical requirements except the linear measurement range are fulfilled to conduct propofol monitoring in breath.

\section{Acknowledgements}

The data were generated by Larissa Walter (Biomedical Science, Reutlingen University, Germany) during her bachelor thesis. This work was financially supported by B\&S Analytik (Dortmund, Germany). JIB, TV and SK declare a conflict of interest. All devices were loaned by B.Braun Melsungen (Melsungen; Germany).

\section{References}

[1] J.B. Glen, F. Servin, Evaluation of the predictive performance of four pharmacokinetic models for propofol, Br. J. Anaesth. 102 (2009) 626-632, http://dx.doi.org/10.1093/bja/aep043.

[2] G.R. Harrison, Real-time breath monitoring of propofol and its volatile metabolites during surgery using a novel mass spectrometric technique: a feasibility study, Br. J. Anaesth. 91 (2003) 797-799, http://dx.doi.org/10.1093/ bja/aeg271.

[3] A. Takita, K. Masui, T. Kazama, On-line monitoring of end-tidal propofol concentration in anesthetized patients, Anesthesiology 106 (2007) 659-664, http://dx.doi.org/10.1097/01.anes.0000264745.63275.59.

[4] M. Grossherr, A. Hengstenberg, T. Meier, L. Dibbelt, K. Gerlach, H. Gehring, Discontinuous monitoring of propofol concentrations in expired alveolar gas and in arterial and venous plasma during artificial ventilation, Anesthesiology 104 (2006) 786-790, http://dx.doi.org/10.1097/00000542-200604000-00024.

[5] Q. Zhou, W. Wang, H. Cang, Y. Du, F. Han, C. Chen, S. Cheng, J. Li, H. Li, On-line measurement of propofol using membrane inlet ion mobility spectrometer, Talanta 98 (2012) 241-246, http://dx. doi.org/10.1016/j.talanta.2012.07.001.

[6] P.R. Boshier, J.R. Cushnir, V. Mistry, A. Knaggs, P. Španěl, D. Smith, G.B. Hanna, On-line, real time monitoring of exhaled trace gases by SIFT-MS in the perioperative setting: a feasibility study, Analyst 136 (2011) 3233-3237, http://dx.doi.org/10.1039/c1an15356k.

[7] C. Berchtold, M. Bosilkovska, Y. Daali, B. Walder, R. Zenobi, Real-time monitoring of exhaled drugs by mass spectrometry, Mass Spectrom. Rev. 33 (2014) 394-413, http://dx.doi.org/10.1002/mas.21393.

[8] E. Carstens, A. Hirn, M. Quintel, J. Nolte, M. Jünger, T. Perl, W. Vautz, On-line determination of serum propofol concentrations by expired air analysis, Int. J. Ion Mobil. Spectrom. 13 (2010) 37-40, http://dx.doi.org/10.1007/s12127010-0036-7.
[9] T. Perl, E. Carstens, A. Hirn, M. Quintel, W. Vautz, J. Nolte, M. Junger, Determination of serum propofol concentrations by breath analysis using ion mobility spectrometry, Br. J. Anaesth. 103 (2009) 822-827, http://dx.doi.org/ $10.1093 / \mathrm{bja} / \mathrm{aep} 312$.

[10] F. Maurer, M. Geiger, T. Volk, D.I. Sessler, S. Kreuer, Validation of liquid and gaseous calibration techniques for quantification of propofol in breath with sorbent tube Thermal Desorption System GC-MS, J. Pharm. Biomed. Anal. 143 (2017) 116-122, http://dx.doi.org/10.1016/j.jpba.2017.05.042.

[11] W. Vautz, M. Schmäh, HovaCAL ${ }^{\boxplus}$-a generator for multi-component humid calibration gases, Int. J. Ion Mobil. Spectrom. 12 (2009) 139-147, http://dx. doi.org/10.1007/s12127-009-0030-0.

[12] ICH Topic Q2 (R1) Validation of Analytical Procedures: Text and Methodology, Int. Conf. Harmon. 1994 (2005) 17. http://www.ich.org/fileadmin/Public_Web_ Site/ICH_Products/Guidelines/Quality/Q2_R1/Step4/Q2_R1_Guideline.pdf.

[13] C. Hornuss, M.E. Dolch, S. Janitza, K. Souza, S. Praun, C.C. Apfel, G. Schelling, Determination of breath isoprene allows the identification of the expiratory fraction of the propofol breath signal during real-time propofol breath monitoring, J. Clin. Monit. Comput. 27 (2013) 509-516, http://dx.doi.org/10. 1007/s10877-013-9452-7.

[14] S. Kamysek, P. Fuchs, H. Schwoebel, J.P. Roesner, S. Kischkel, K. Wolter, C. Loeseken, J.K. Schubert, W. Miekisch, Drug detection in breath: effects of pulmonary blood flow and cardiac output on propofol exhalation, Anal. Bioanal. Chem. 401 (2011) 2093-2102, http://dx.doi.org/10.1007/s00216011-5099-8.

[15] C. Hornuss, D. Wiepcke, S. Praun, M.E. Dolch, C.C. Apfel, G. Schelling, Time course of expiratory propofol after bolus injection as measured by ion molecule reaction mass spectrometry, Anal. Bioanal. Chem. 403 (2012) 555-561, http://dx.doi.org/10.1007/s00216-012-5856-3.

[16] Y. Gong, E. Li, G. Xu, H. Wang, C. Wang, P. Li, Y. He, Investigation of propofol concentrations in human breath by solid-phase microextraction gas chromatography-mass spectrometry, J. Int. Med. Res. 37 (2009) 1465-1471, http://dx.doi.org/10.1177/147323000903700522.

[17] S. Kreuer, a Hauschild, T. Fink, J.I. Baumbach, S. Maddula, T. Volk, Two different approaches for pharmacokinetic modeling of exhaled drug concentrations, Sci. Rep. 4 (2014) 5423, http://dx.doi.org/10.1038/srep05423.

[18] D. Ziaian, R. Herrmann, K. Kleiboemer, A. Hengstenberg, M. Grossherr, S. Brandt, H. Gehring, S. Zimmermann, A.E. Berggreen, Pharmacokinetic modeling of the transition of propofol from blood plasma to breathing gas, in: 2014 IEEE Int. Symp. Med. Meas. Appl., IEEE, 2014, pp. 1-5, http://dx.doi.org/ 10.1109/MeMeA.2014.6860035.

[19] F. Maurer, D.J. Lorenz, G. Pielsticker, T. Volk, D.I. Sessler, J.I. Baumbach, S. Kreuer, Adherence of volatile propofol to various types of plastic tubing, J. Breath Res. 11 (2017) 16009, http://dx.doi.org/10.1088/1752-7163/aa567e.

[20] C. Hornuss, S. Praun, J. Villinger, A. Dornauer, P. Moehnle, M. Dolch, E. Weninger, A. Chouker, C. Feil, J. Briegel, M. Thiel, G. Schelling, Real-time monitoring of propofol in expired air in humans undergoing total intravenous anesthesia, Anesthesiology 106 (2007) 665-674, http://dx.doi.org/10.1097/ 01.anes.0000264746.01393. e0. 